\title{
The E-learning system used in the civil servants' job-training
}

\author{
Rui Yang, Jianhai Ruan \\ College of Computer \& Information Science, Southwest University, \\ Tian Shengqiao Road 2, Chongqing 400715, P.R.of China \\ Email:yr1026@163.com \\ Email: rjh@swu.edu.cn
}

\begin{abstract}
The Chinese government is pursuing e-learning policies which makes job-training with a knowledge-based society. To explain more fully the important role of the e-learning environment, this article undertakes some typical examples of the governments' job-training under e-learning environment. The main problems in servants' job-training in China are the low quantity in the servants' training, short of restriction, the uniform manner in the training and less fairness and availability of opportunities for educational training. In order to develop the e-learning system, the civil servant's jobtraining policies are provided and the measures of the effective e-learning system are designed.
\end{abstract}

\section{Introduction}

In the knowledge-based society, the sharing and expansion of knowledge and information are the key factors for social development. Many nations around the world have created key policies for developing e-learning police; e-learning has emerged as a new alternative in job-training. The initiative to develop civil servants through e-learning has been widely adapted by the China government as e-learning overcome the limits of time and space and contributes to knowledge expansion through interaction.

Of all the educational technologies that have exhibited great potential, e-learning appears to be the most promising. Essentially, the e-learning system predominantly provides information, not instruction or other pedagogical supports for learning $[1,2]$ What is e-learning? E-learning can be defined as the most recent evolution for distance learning [3]. In its broadest definition, e-learning includes instruction

Please use the following format when citing this chapter:

Yang, R., Ruan, J., 2007, in IFIP Intenational Federation for Information Processing, Volume 252, Integration and Innovation Orient to F-Society Volume 2, eds, Wang, W., (Boston: Springer), pp. 574-581. 
delivered via all electronic media, including the Internets, intranets, extranets, satellite broadcasts, audio/video tapes, interactive TV, and CD-ROM[4]. E-learning has been introduced into governments and other public sectors as a new learning and training mode in many countries and regions.

\section{Execution and background of e-learning in China}

The conception of "e-learning" was introduced into China only several years. There are few successful examples for the e-learning in China, except the multinationals which full of experience on e-learning. In a word, there is a big development potential in our home market, but it is still a long way to go. As the pioneer of the modernization, the government should create a better environment for the e-learning technology.

E-learning is a very useful way for job-training especially the basic training. Now many governments establish government universities on line. For instance the Shanghai official on-line(http://www.shgb.gov.cn/); and the e-learning project of Yunnan province. After fulfilling the e-learning of e-government in Yunnan, the system will give the training for civil servants from 53 departments. The main technologies of the system are Linux or Unix/windows server, java language; and the databases are oracle or SQL-server.

There are some other cases of the civil servants' job-trainings under the online environments in China:

- China e-government

( http://www.e-gov.org.cn/peixun/) It provides some information about the job-training. This isn't a real e-learning, though it also lists some course such as spoken-English training, java script and senior system engineer, etc...

- Party school of the central committee of the Party

(http://www.ccps.gov.cn/index.jsp)The web-learning provide the contents as follow: Graduate student education, distance education, scientific research of the party school, informatization, campus management

- The servants' on-line learning of Ningbo (http://www.nbstudy.gov.cn/)The main job-training settings of this elearning environment are required courses, elective courses, public speech and self tests. All the servants need a learning ID and password to enter in.

\section{The underutilization of the e-learning used in the governmental job-training}

Internet communication training has had a positive influence in promoting the growth of e-learning within civil servants. This development can also be evaluated as an important result of the Internet communication training policy. However, despite the notable success in promoting government e-learning, there are still problems 
within the existing system that have to be addressed. These problems within government e-learning, however, cannot be said to originate in the Internet communication training system itself. Rather, the problems seem to lie in the fact that no systematic and varied efforts have been made to overcome and compensate for some of the present limitations in government e-learning.

\subsection{Lower quality of the civil servants' training}

Compared with the west countries, the government training in China remains room to develop. Not surprisingly, "course quality" is the most important concern in this elearning environment. Course content should be carefully designed and presented sparingly [5]. The problems are (a) governments don't take the servants' training seriously. On the governments' side, they didn't take the training as the one important way of the human resource management. On the other hand, because of the lack of the publicizing, the servants didn't pay enough attention to the civil servants' training either. (b) Some of the courses are out of data, so they can't be satisfied with every servant's need. (c) Because of the fund of the civil servants' training is limited, many of the training can't provide profound education materials. All the problems above lead a lower quantity of the servants' job training in China.

\subsection{Ineffective motive mechanism}

In order to resolve the problems like lower motivation, lower enthusiasm of the job training, the government must complete the motivation mechanism. The government should consider the training grade as the civil servants' job achievements, and the government also should list the grade in the servants' archives. Those who don' take part in the training with no reasonable excuse and who don't get enough marks should be evaluated eligible and should not be prompted until they make up a missed lesson. So generally speaking, unless the governments build the effective motive mechanism, the servants won't inspire a strong learning volition and won't take part in the job training actively.

\subsection{The uniform manner of training}

The problem of uniform can be said to be magnified. More specifically, the problems arise from the fact that many of the Internet communication training courses prepared for government educational training are uniform in terms of their fields of knowledge, types of training, target users, levels, and development methods. Not only are the same courses being developed and taught, so they overlap, but they also tend either to be too theory-oriented or concentrated in only certain easy fields. Development methods also tend to be uniform, unable to fulfill the diverse and specialized needs of governments. 


\subsection{Disproportion in the fairness and availability of opportunities for educational training}

There are also problems in terms of faimess and balance in educational training opportunities. Currently, the main beneficiaries of Internet communication training systems tend to be the office administrative staff of governments. When governments administered their own training programs, it was fount that all the courses, with the exception of one, were being targeted at leaders.

\section{E-learning system used as job-training tools}

Today, governments are making great effort to properly adjust to the change learning environment to enhance their competitiveness. In step with the development of information technology and the Internet, many governments are replacing traditional vocational training with e-learning.

The Interment and World Wide Web have provided opportunities of developing e-learning systems. The goal of introducing a training program is to increase task ability with advanced trainees' knowledge, technology and attitude.

\subsection{To reform the training policy}

The measurements of reforming the training policy are as follow:

\subsubsection{To promotion by the result of the job-training}

According to the report during the Eleventh Five-Year Plan period, all the civil servants will be examined comprehensively. The goal of examination is to improve all the servants' political thinking and the vocation abilities. What's more, the government will launch a principle which will take the servants' learning grade as one of the conditions of prompting.

(http://www.gmw.cn/content/2007-02/26/content_558387.htm)

\subsubsection{To take work efficiency into count}

The goal of the e-learning system is to improve the efficiency of the human resource. Task-related content directly affect trainee's learning performance. So if the government wants to improve the work efficiency by using e-learning, they must induce the e-learning into the every day's work. For instance, for the servants who need more practice, the e-learning should help them practice the work skillfully. For the other servants whose works on the datum, document and information management .etc, e-learning should help them how to deal with such work efficiently. Of course, all these above need a completive plan of e-learning. 


\subsubsection{To build a better learning environment}

In order to remove the negativity from the servants, the governments and other public sectors should build a well learning environment inside the organizations. The civil servants should realize that "work" and "learning" are not opposite, but the two sides of one thing. Learning is the core of work, and the process of work is a process which is a kind of self-training and learning among all the staff. So if the governments want to build a well learning environment they must (a) The civil servants' e-learning must be supported by the office administrative staff of governments. The government leader themselves should take part in the e-learning and admit the new thinking and learning methods. (b) Harmonize the e-learning and other learning methods. Build a proper learning system, and create a completive learning environment step by step. (c) An effective motivation mechanism can help us build a good learning environment.

\subsubsection{To reform the training methods}

The civil servants' learning must turn from the traditional education methods to modern education methods. We must develop some scientific methods and use the web technology such as the www, E-mail and computer conference also can be combined with print materials. On the other hand, the e-learning can also choose a flexible timetable such as long-term learning, short-term learning and work-study program. In one word, in order to deal with the contradiction between work and trainings, the time problem must be well-handled.

\subsubsection{To evaluate the training}

Reaction and learning are studied as major indicators of training outcomes; however, these variables are not the appropriate indicators of the final desired outcome of training programs-transference of learning to the job. An appropriate evaluation of training outcomes is made by measuring changes in job performance and relating it to measurements of achievement of learning goals [6].

Evaluation is conducted after completing of a course or program. It shows the degree of accomplishment of program objectives. And of course program evaluation procedures can improve instruction significantly and also can serve as justification for continued effort or support in civil servants' lifelong learning. Evaluation is important because the outcomes of the evaluation can be used for more up-to date, more effective, and more efficient instruction in the future. The advantages of a webbased system will become easier because updates in web-courses are easier and faster to implement than with traditional education. 


\subsection{To design an effective system}

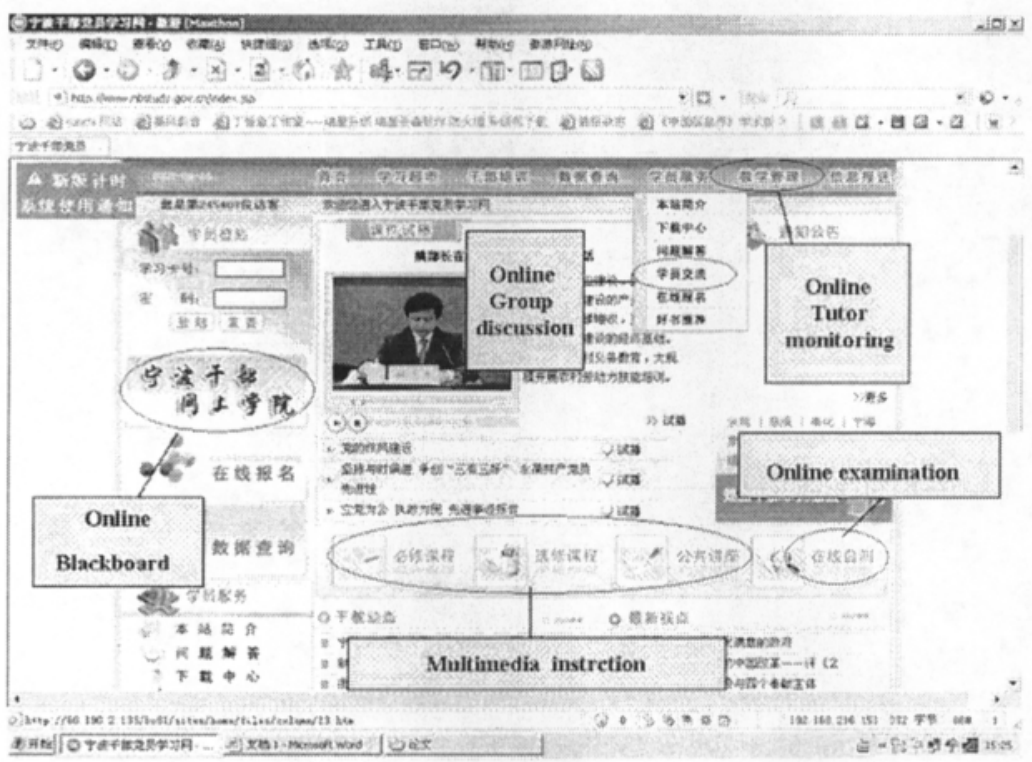

Fig. 1. The e-learning system

In general, e-learning refers to the use of Internet technologies to deliver a broad array of solutions that enhance knowledge and performance [7]. In other words, when an online site is designed, the site's ease of use should be considered important factors.

The e-learning system is a web-based system. Thus, it can be plugged into web browsers when civil servants use it as a learning assisted tool. The major functions of the e-learning system include: [8] multimedia instructional content, group discussion function, blackboard function, tutor monitoring function and e-learning system. First, based on the e-learning system, it supports nonlinear networks to access information, and instructional formats are ill-structured and networked. Secondly, it offers a multimedia environment where instructional contents are driven by multimedia. Third, it supports interactive communication and random-access network, thus activities are performed cooperatively and collaboratively. Fourth, based on the system, it provides a cross-platform environment. And fifth, it support interactive communication and cross-platform environments that accommodate learning activities. Fig1 shows such e-learning system.

The governments will create better online courses that ensure servants have access to high-quality course content, interaction among small groups of servants and colleagues. In my opinion an e-learning environments should be build and maintained as follow: 
- Technology will be used to incorporate active and collaborative, resourcecentered learning into general government courses.

- Key courses will be easily shared among governments or departments, civil servants from many departments into a single learning community.

- Traditional face-to-face courses will routinely include on-line elements as part of courses, and let every servants take part in.

- Enable members within a unit will be able to share online learning objects efficiently across individual courses in training and to ensure consistent quality in the presentation of content at all locations where a course is taught.

- Enable members will be able to store, access, and re-purpose digital course contents.

- Some government programs will be extended outside its own city and share through all the cities around China by using the e-learning environment.

- All faculty servants will have the opportunity to incorporate some level of online learning in their courses.

- All the civil servants, regardless of post and rank, will have the opportunity to participate as active producers, not just consumers, of web-based knowledge.

In order to realize this vision, the government requires an e-learning environment that integrates four elements of on-line learning. It refers to the distance education of pedagogic [9]:

(1) Creation of course modules: The quality of the e-learning experience follows from the quality of the course modules and of the interactions among trainers and servants that make up online courses. The faculty members, servants, and instructional staff who design and produce on-line course modules need access to powerful tools and reliable training strategies.

(2) Management of course modules: Innovative database management practices are required to facilitate efficient revision and re-purposing of course modules and to foster sharing of modules among servants and programs. Responsibility for this element is shared among departments, local governments support facilities

(3) Delivery of courses: At the core of the common e-learning environment is a delivery system that makes course modules available on-line, mediates interactions between the government and the servants, and helps the government to efficiently manage servants' records.

(4) Delivery of support services: All the civil servants---in government or off--deserve access to technical support, digital library resources and other key aspects of the government experience. A common e-learning environment will help facilitate this access.

The following considerations are also crucial in designing e-learning environment: keeping up servants' motivation and providing reinforcement, making direct assistance available, providing ongoing technical services, assuring easy access to computer and modem, ensuring that the network software system is appropriate for the application and available for the duration and extent required, and assuring the servants are at the appropriate level of computer usage. 


\section{Conclusion}

E-learning in the civil servants' job-training is attracting interest not simply as a tool for innovating the civil servants' job-training and developing education system, but also for prompting social cohesion, actualizing educational welfare and encouraging international cooperation. Online learning is an alternative to traditional face-to-face education. Many governments are going to use e-learning to meet servants' needs, especially those of non-traditional servants with full time jobs. Since e-learning is conducted using the Internet and World Wide Web, the learning environment becomes more complicated. Servants' initial perceived satisfaction with technologybased e-learning will determine whether they will use the system continually.

Even though the e-learning's execution currently has a growth potential in China, the overall degree of social use is still low in China. Institution measures that take into consideration the needs of users are especially weak. Accordingly, in addition to fully reforming the job-training of the governments, legal systems, e-learning systems and the proper mechanism related to educational informatization and elearning must be established in China.

\section{References}

1. S.S. Liaw andH. M. Huang, "Enhancing interactivity in Web-based instruction: A review of the literature", Educational Technology ,40(3), 41-45(2000).

2. S. Vosniadou, "Toward a revised cognitive psychology for new advances in learning and instruction", Learning and Instruction, 6(2), 95-109(1996).

3. R.T. Raab andW.W. Ellis and B.R. Abdon, "Multisectoral partnerships in elearning: a potential force for improved human capital development in the Asia Pacific", Internet and Higher Education ,4 (3-4), 217-229 (2002).

4. T. Govindasamy, "Successful implementation of E-learning: pedagogical considerations", Internet and Higher Education, 4 (3-4), 287-299(2002).

5. P.C. Sun, J. Ray, Tsai and F. Glenn, "What drives a successful e-learning? An empirival investigation of the critical factors influencing learner satisfaction", Computers\&education, 2007,1-20 (2006).

6. K. Kreiger, J. K. Ford and E. Salas, "Application of cognitive, skill-based, and affective theories of learning outcomes to new methods of training evaluation", Journal of Applied Psycholog,y 78, 311-328(1993).

7. M.J. Rosenberg, E-learning, strategies for delivering knowledge in the digital age, New York: McGraw Hill (2001).

8. S.S. Liaw, H.M. Huang and G.D. Chen, "An activity-theoretical approach to investigate learners' factors toward e-learning systems", Computers in Human Behavior 23(2006).

9. Hohn T Harwood.

http://www.web.psu.edu/archive/e-learning\%2orepart\%20051310.pdf. 